\title{
A Study on the TV Commercials of Luxury Female Perfumes
}

\author{
Xiuqin Zeng \\ School of Journalism and communication, \\ Xiamen University, \\ Xiamen, China
}

\begin{abstract}
Audiences are exposed to more and more TV commercials of luxury goods, including perfumes. This paper analyzes TV commercials of female perfumes and fragrances from four luxury brands, namely Coco Chanel, Christian Dior, Lancôme and FestLauder. By using content analysis method, This study discusses the creativity and expression patterns in the choosing of themes, spokespersons, copies, background music and etc. Finding is discussed in regard to luxury product ad.
\end{abstract}

Keywords - content analysis; expression patterns; TV commercial; luxury goods

\section{INTRODUCTION}

As the best example of a combination of art and commerce, luxury goods have made a great contribution on the world economy, politics, culture, art, etc. In the field of marketing and advertising, luxury goods industry gathered the industry's top talent, its marketing practices provides us with a wealth of material. As an important part of the luxury industry, perfume is considered as "the interfaces of general public and the world of luxury." Compared to expensive jewelry and couture, the perfume price within the range of the general public can afford, and the same can be, bring owners brand cultural experience, like the jewelry and fashion do. By studying the perfume ad forms, we expect to find out the marketing and creative practices behind the luxury goods industry, by analyzing the characteristics of different perfume ads to find such a creative advertising model to guide us to effectively conduct the campaign, more importantly, provide a reference for China to develop its own high-end perfume and luxury brands.

\section{THEORY REVIEW}

\section{A. Development of Perfume Television Advertising}

In 1953, Marilyn Monroe, in an interview, volunteered to made endorsement for Chanel No. $5^{[1]}$, who said the advertising slogan which is still captured the hearts of countless: "I only wear Chanel 5 for sleeping." Marilyn Monroe's endorsement may not premeditated, but was later deemed to be Chanel's TV ads. Whatever, this event has become a classic in the history of perfume, still consciously or unconsciously being used for advertising purposes, its effect and impact beyond doubt.

The glorious of perfume industry began in the late 19th century, the rise of its television advertising began around the end of 20th century to the early 21st century. Typically, the high-end products mainly provide for a

\author{
Shuo Wang \\ School of Journalism and communication, \\ Xiamen University, \\ Xiamen, China
}

small number of consumer, they are inclined to choose media advertising platform, like magazines, which is more targeted, can precisely target specific consumer. But in the high-end perfume and cosmetics industry, television advertising accounted for the most of the total advertising; while in choosing perfume product advertising media, the proportion was $61 \%$. It also reflects the broad consumer groups of perfume and its status as a " window for public to understand the luxury brands " [2].

\section{B. Research Hypothesis}

According to the Product life cycle theory, the product's life ,from birth to death, can simply classified as five different process stages, which namely called the typical product life cycle S curve ${ }^{[3]}$. Changes in the product life cycle and marketing approaches used are closely related. Bo Yang(2008) believed that advertising style located in the creative process which displays the art feature and creative personality ${ }^{[4]}$. Grasp the different marketing characteristics at different stages of the product life cycle, and compliance, reflect these features in the ad creation, it is the decisive factor in the formation mechanism of the advertising style. Therefore, this study proposes the first hypothesis H1.

H1: different characteristics existed in different marketing cycle of perfume television advertising;

High-end brand use perfumes to convey image and brand connotation to general consumers. Companies who develop perfume products is by no means only for profit, perfume have a closely relationship with the brand building and delivering the brand values and culture ${ }^{[2]}$. Ramaprasad et al (1995) also pointed out that culture is the most important environmental factors affecting $\mathrm{ad}^{[5]}$. In view of the close relationship between perfume products and its respective brand, then, this study proposes a second hypothesis $\mathrm{H} 2$.

H2: Perfume belong to distinctive Brand whose TV ads have different characteristics

\section{RESEARCH METHODS}

\section{A. Study Object}

The study objects are defined as 38 women's perfume TV commercials of four brands ,like Chanel, Dior, Lancome, Estee Lauder since 2000. These TV ads information is obtained from the above four brand's official website and news reports which releasing, then, through YouTube, Youku and other large domestic and 
foreign video sharing sites to download the TV ads released since 2000 .

\section{B. Reliability Between Coders}

In this study, two coders participate in the sample encoding process, using Scott (Scott) Pi to calculate the reliability index between two coders. "the theme of Plot ",due to the effect of subjective cognitive performance, $\mathrm{Pi}$ index ,which is less than 1 , is .923; other coding project are objective information, without influence of coders, Pi index is 1 .

\section{Data Analysis}

After encoding is completed, use SPSS software to analyze the data and test hypotheses.

\section{RESULTS AND DISCUSSION}

\section{A. Spokesmen Features}

38 ads are all chosen celebrity as their product endorsements. Spokesmen were all female, and the identity of whom only classified as two sorts: movie stars and models, the proportion was respectively $58.0 \%$ and $42.0 \%$. Overall, the difference between the number of star endorsement ads and models endorsement ads is not obvious.

After the cross analysis of the period of marketing and advertising spokesperson identity, chi-square test significan $\left(\chi^{2}=10.53, d f=4, p<0.05\right)$, therefore, hypothesis $\mathrm{H} 1$ is accepted. The results showed that when the product is lied in initial stage, advertising tend to choose a models as their product's spokesperson; movie stars tend to appear in repeated promotion stage. The data also show that there are no preference differences when choosing a spokesperson for the new products of existing series. In this condition, the Initial assumptions of author is that, advertising at this marketing period is unique, it can not only promote its existing fragrances, but also promote its new product, thus, choice of spokesmen is greater flexibility.

TABLE I . SPOKESPERSON'S IDENTITY AND ADVERTISING MARKETING CYCLE ANALYSIS TABULATED IN UNION

\begin{tabular}{lccc}
\hline \multicolumn{1}{c}{ Marketing Cycle } & $\begin{array}{c}\text { Movie } \\
\text { star }\end{array}$ & Model & Sum \\
\hline $\begin{array}{l}\text { The new products of } \\
\text { new series }\end{array}$ & 13.2 & 23.7 & 36.8 \\
& $(5)$ & $(9)$ & $(14)$ \\
$\begin{array}{l}\text { The new products of } \\
\text { existing series, }\end{array}$ & 10.5 & 10.5 & 21.1 \\
& $(4)$ & $(4)$ & $(8)$ \\
$\begin{array}{l}\text { Duplicate promotion } \\
\text { of Existing product }\end{array}$ & 34.2 & 7.9 & 42.1 \\
\multicolumn{1}{c}{ Sum } & $(13)$ & $(3)$ & $(16)$ \\
& $(22)$ & $42.1(16)$ & 100.0 \\
\end{tabular}

\section{B. Features of the Ads Length}

According to statistical analysis, the average length of all the perfume ads is 44 seconds, but different marketing cycle length's difference is very obvious. T new series of new product advertising with the shortest length and an existing series product advertising have the longest length, new product of existing series betwixt in both. With time increasingly rise, Product putting into the market, not only failed to advertising shorten , but have an clear upward trend. $F$ test $(F=3.54, d f=2, p$ $<0.05$ ) showed that, in different marketing period, there were significant differences between the product advertising length. $\mathrm{H} 1$ being confirmed again.

The average length of Comprehensive luxury brand perfume ads $=41.32$ cosmetics industry brand perfume ads's average length $=85.63$, the former is about twice times as the latter. $\mathrm{T}$ test results showed $(T=4.56, d \mathrm{f}=$ $37, p<0.001$ ), there were significant differences among different brands categories in ads length. H2 be verified.

\section{Features of Ad Theme}

The theme of television advertising perfume can be fundamentally grouped into the following six categories, of which, nearly half of the advertising theme is "have fun, enjoy", followed by "Love Story", accounting for $28.9 \%$ of all topics; while "sexual suggestion" themes and "products" themes is generally believed have correlation with perfume are only $5.3 \%$ of the population.

Analysis of the correlation between advertising themes and marketing cycle, the results shown in Table 3 . Correlation into chi-square test $\left(\chi^{2}=15.58, \mathrm{df}=10, \mathrm{p}>\right.$ 0.05 ), the results showed no significant association between the two, advertising marketing period does not affect the selection of ad theme.

\section{The Features of Ad Copy}

The television advertising copywriting among different Brand perfume demonstrated a remarkable consistency. 38 ads, in addition to 3 ads who have narrators, 2ads applied mixed forms, the other 33 ads have no dialogue, only appears at the end of the product and read the product name. Regardless of whether the advertising spokesperson dubbing, sounds mostly appear (32 ads) in the form of narration, very few ads appear the picture where spokesperson directly read out the name of the product ( 2 ads). In addition, every sentence at the end of ad copy is simple, roughly the same pattern, are " product name +brand name " (32 ads); if it is new product ads, apart from the product names and brand names appeared at the end of ad, it also specially stressed the concept of "new" in the copy of the ad(2 ads).

\section{E. The Features of Background Music}

Sound track in Perfume TV commercial, 50\% of the background music lyrics are in English, $42.1 \%$ of pure music without lyrics, only two background music lyrics in French and one Italian. Compare brands Categories and the selection of background music, it can be found that in the comprehensive category of luxury perfume brand advertising tend to use background music with lyrics, background music without lyrics are almost used by cosmetics brands. Results of Chi-square test is ( $\chi 2=7.549, d f=1, p<0.05)$, therefore, hypothesis H2c can be accepted, which confirmed that there is a significant 
correlation between the choices of background music and the attributes of industry.

In addition, the perfume ads tend to choose old classic songs, up to now, those songs have an average of 30.48 years, in the comprehensive luxury brands that number is larger, the average elapsed 42.33 years. T test showed ( $t=2.32, d f=15, p<0.05$ )that there were significantly difference between two brand categories in the background song's which support the hypothesis H2c again.

\section{F. The Features of Ad Scenes}

38 perfume ads, 13 ads have occurred in the indoor scenes, 12 have occurred in the outdoor (in which 9 ads occurs in natural surroundings, 3 occurred in the city scenes ), 7 ads occurred in a mixed scenario, 6 have no advertising scenes feature. According to the content analysis, we found that: Either ad scene, the hero of the ad showing the habits and attitudes are consistent. The layout structure of Ad indoor scene show more similar to the palaces and castles, most are ancient decoration; outdoor scene - whether urban or natural environment has emerged as a natural quiet aristocratic style. Overall, these scenes, where is showing, which ordinary people can't achieve, is terrestrial, is longing and envy for common people. These high-end perfume television advertising picture hardly appear modern building, articles or scenes. Even if the story occurred outside of the city, but exhibits a non-modern cityscape.

Compare different brands property of perfume TV commercial, you can find two types brand differ in the choice of advertising story scene: Comprehensive luxury brand perfume ads taken place in addition to a city outdoor advertising scene, the other ads are not alone occurred in outdoor scenes, especially scenes of nature, while cosmetics perfume ad tend to occur in outdoor scenes, especially in the natural environment. Using the chi-square to test the correlation between advertising scenes and brand category, the result is $\chi 2=11.064, \mathrm{df}=$ 4 , $\mathrm{p}<0.05$, therefore, the hypothesis H2d can be accepted, correlation between the selection of advertising scenery and the brand category which product belongs was significant.

\section{DISCUSSION}

According to the results discussed above, you can find the high-end female perfume of TV ads have model to follow in its expression - extraordinary influence spokesman, lavish retro or fresh and natural location, extreme enjoyment of life story. As a perfume ad spokesperson, supermodel and well-known actress not only as the anthropomorphic image of perfume products, but play an important role in other marketing promotion occasions, which is the reason, in a different period of product marketing, have differences in the choice of spokesperson. The selection of scenery is committed to give the general public a bit of distance as much as possible, highlighting the high-end nature. The pursuit of self-enjoyment of the story is to show product image and the core element of brand value, and is the key of competition. In addition, for the perfume, the smell, packaging are all tangible, the core product of perfume is providing consumers with abstract expectations and different enjoyable connotation. So TV ads in expressing this core demands, tend to pay more attention to images and music to create an atmosphere rather than using copy transfer abstract conception.

Therefore, for future high-end perfume ads, the influence of spokesperson, shooting scenes features and the theme of story are unlikely to change. After all, the atmosphere and the pursuit of high-end luxury goods are the fundamental of perfume; spokesperson's influence is also the fundamental of high-end brand campaign. In other respects, the enterprise should subvert the traditional model in different aspects as much as possible, such as Chanel hired male celebrity as an endorsements for Women perfume. From a marketing point of view, the choice of tactics, some perfume television advertising has transited to "micro-movie" mode, which throughout television and Internet media. In the future, investment of advertising length may be greater, perhaps there will be longer "serial type" ads. Relations between perfume and movies are so closely, so the television advertising will increasingly become more cinematic.

For the development of China's own high-end perfume products, in the short term, the possibility of domestic high-end luxury brand or cosmetic brands is small, therefore, if the perfume aim to Chinese consumer, with Chinese culture and characteristics, there are two existing possibilities: First, some foreign luxury brand for opening up China market, so they develop such products, the second, China's well-known fashion designers devote to developing the local perfume production line. For the future of China's television advertising perfume, first, we should pay more attention to the choice of spokesperson. China has a lot supermodel who are all fashionable, but the reputation in domestic is unknown; well-known actor can bring good effect for promotion, but, if the new brand can't be touch the heart of consumer, they may link the perfume with a star's charm, so the choice must take its image into consideration. In the design of episode, you can refer to foreign case, the design of script and shooting supervision should be done by the well-known director and artistic director. The most difficult part must be the selection of shooting background and story design, with the rapid development and change of Chinese society, modern values greatly affected by various factors, the attitude of domestic consumers when deal with perfume products suffered mainly from the impact of foreign products, thus, search for a different style but can accurately locate Chinese consumers' "Chinese style" is difficult. These two elements referred to the design of the product positioning, so you can refer to Revlon "Charlie" perfume case, insight into the potential of ideology from the modern society, make a position for product which can fit the image of a particular social environment. This will not repeat them here.

\section{References}

W1] Wikipedia.
http://en.wikipedia.org/wiki/Chanel_No._5, 2012-5-8. No.5. 
[2] M. Tungate. "Fashion Brands Branding Style from Armani to Zara". London and Philadelphia: Kogan Page, 2008.

[3] G. Armstrong, S. Adam, S. Denize, \& P. Kotler. "Principles of marketing". Pearson Australia, 2014.

[4] B. YANG. "The Style of Ads and the Life Cycle of Products". Commercial Research, 2008,10: pp83-85.
[5] J. Ramaprasad, J. Wu, and D. Gao. "A Conceptual Framework for Undestanding the Content of Advertising: Its Application to the Specific Case of Chinese Television Commercials". Asia Journal of Communication, 1995, 5: pp88 100 